\title{
Will the Stroma-derived Factor-1 $\alpha$ (CXCL12)/CXCR4 Pathway Become a Major Concern for Advanced Colorectal Cancer?
}

\author{
Hungdai Kim \\ Department of Surgery, Kangbuk Samsung Medical Center, Sungkyunkwan University School of Medicine, Seoul, Korea
}

\section{See Article on Page 27-34}

The chemokine stroma-derived factor (SDF-1 $\alpha /$ CXCL12) is a homeostatic chemokine. The major function of this chemokine is to regulate hematopoietic cell trafficking and secondary lymphoid tissue architecture [1]. SDF-1 $\alpha$ is also widely expressed in various organs. Including the heart, liver, brain, kidney, skeletal muscle, and lymphoid organs, and it plays multiple roles in tumor pathogenesis. SDF-1a has been demonstrated to promote tumor growth, enhance tumor angiogenesis, participate in tumor metastasis, and contribute to immunosuppressive networks within the tumor microenvironment. SDF- $1 \alpha$ expression is reported in ovarian cancer, breast cancer [2], colorectal cancer, pancreatic cancer, prostate cancer, thyroid cancer, and many other human tumors.

SDF- $1 \alpha$ can increase the invasiveness and the migration of cancer cells, and its levels are correlated with node involvement and long-term survival in patients with breast cancer. SDF-1 may, therefore, have potential value in assessing clinical outcomes of patients with breast cancer [3]. Although colorectal cancer (CRC) tissues contain SDF-1 $\alpha$-positive stromal cells, immunohistochemistry clearly demonstrated that the cancerous cells in more than $50 \%$ of the CRC samples examined had much stronger expression of SDF-1 $\alpha$ than their neighboring normal colonic epithelial cells. Accordingly, as with CXCR4 overexpression, the SDF-1a/CXCR4 pathway appears to play important roles in the progression of CRC [4].

In this study, the authors merely measured the SDF- $1 \alpha$ expression level in the normal colonic mucosa and in colorectal

Correspondence to: Hungdai Kim, M.D.

Department of Surgery, Kangbuk Samsung Medical Center, Sungkyunkwan University School of Medicine, 29 Saemunan-ro, Jongno-gu, Seoul 110-746, Korea

Tel: +82-2-2001-2137, Fax: +82-2-2001-2131

E-mail: hungdai.kim@samsung.com

(c) 2012 The Korean Society of Coloproctology

This is an open-access article distributed under the terms of the Creative Commons Attribution NonCommercial License (http://creativecommons.org/licenses/by-nc/3.0) which permits unrestricted noncommercial use, distribution, and reproduction in any medium, provided the original work is properly cited. cancer tissue. If this study had included the SDF-1a specific receptor CXCR4 expression level, the authors would have obtained better results. Nevertheless, the results are quite impressive. SDF-1a expression was highly correlated with pericolic lymph-node metastasis, distant metastasis, tumor-node-metastasis stage and lymphovascular invasion. Strong SDF-1a expression was inversely related with patients' survival, suggesting suggest SDF-1a could be a prognostic factor. Further study evaluating the distinctive value of SDF-1 $1 \alpha$ expression in clinical practice may be warranted.

According to the literature, it is evident that manipulation of this pathway represents a new strategy for cancer treatment. CXCR4 antagonists, such as Plerixafor (AMD3100) and T140 analogues (TN14003/BKT140), and blocking antibodies toward CXCR4 or SDF-1 $\alpha$ are being investigated in various cancer settings. In an in vitro study using a colorectal cancer cell line, results indicate that a CXCR4-antagonistic therapy might prevent tumor cell dissemination and metastasis in CRC patients, consequently improving survival [5]. Of course, we need to bear in mind that although targeting CXCR4/CXCL12 is an attractive option in treating human tumors, it is certain that to gain effective, reliable, and consistent clinical efficacy, a definitive combinatorial therapeutic regimen should be found.

\section{REFERENCES}

1. Teicher BA, Fricker SP. CXCL12 (SDF-1)/CXCR4 pathway in cancer. Clin Cancer Res 2010;16:2927-31.

2. Kryczek I, Wei S, Keller E, Liu R, Zou W. Stroma-derived factor (SDF-1/CXCL12) and human tumor pathogenesis. Am J Physiol Cell Physiol 2007;292:C987-95.

3. Kang H, Watkins G, Parr C, Douglas-Jones A, Mansel RE, Jiang WG. Stromal cell derived factor-1: its influence on invasiveness and migration of breast cancer cells in vitro, and its association with prognosis and survival in human breast cancer. Breast Cancer Res 2005;7:R402-10.

4. Yoshitake N, Fukui H, Yamagishi H, Sekikawa A, Fujii S, Tomita S, et al. Expression of SDF-1 alpha and nuclear CXCR4 predicts lymph node metastasis in colorectal cancer. Br J Cancer 2008;98: 1682-9. 


\section{Coloproctology Hungdai Kim}

5. Heckmann D, Laufs S, Maier P, Zucknick M, Giordano FA, Veldwijk MR, et al. A Lentiviral CXCR4 overexpression and knockdown model in colorectal cancer cell lines reveals plerixafor-de- pendent suppression of SDF-1 $\alpha$-induced migration and invasion. Onkologie 2011;34:502-8. 